\title{
X-linked intellectual disability with marfanoid habitus
}

INSERM

\section{Source}

INSERM. (1999). Orphanet: an online rare disease and orphan drug data base. $\underline{X \text {-linked }}$ intellectual disability with marfanoid habitus. ORPHA:776

The Lujan-Fryns syndrome or X-linked mental retardation (XLMR) with marfanoid habitus syndrome is a syndromic X-linked form of intellectual disability, associated with tall, marfanoid stature, distinct facial dysmorphism and behavioral problems. 